\title{
Lower cerebral blood flow is associated with impairment in multiple cognitive
}

domains in Alzheimer's disease

A.E. Leeuwis ${ }^{1}$, M.R. Benedictus ${ }^{1}$, J.P.A. Kuijer ${ }^{2}$, M.A.A. Binnewijzend ${ }^{1,3}$, A.M. Hooghiemstra $^{1,4}$, S.C.J. Verfaillie ${ }^{1,3}$, T. Koene ${ }^{5}$, Ph. Scheltens ${ }^{1}$, F. Barkhof ${ }^{3}$, N.D. Prins ${ }^{1}$, W.M. van der Flier ${ }^{1,6}$.

${ }^{1}$ Alzheimer center \& Department of Neurology, Neuroscience Campus Amsterdam, VU University Medical Center, Amsterdam, the Netherlands

${ }^{2}$ Department of Physics and Medical Technology, VU University Medical Center, Amsterdam, the Netherlands

${ }^{3}$ Department of Radiology and Nuclear Medicine, VU University Medical Center, Amsterdam, the Netherlands

${ }^{4}$ Department of Clinical Neuropsychology, Vrije Universiteit, Amsterdam, the Netherlands

${ }^{5}$ Department of Medical Psychology, VU University Medical Center, Amsterdam, the Netherlands

${ }^{6}$ Department of Epidemiology \& Biostatistics, VU University Medical Center, Amsterdam, the Netherlands

\section{Corresponding author:}

A.E. Leeuwis, MSc

Alzheimer center and Department of Neurology, Neuroscience Campus Amsterdam

VU University Medical Center

P.O. Box 7057

1007 MB Amsterdam

The Netherlands

Telephone: +31204440685

Fax: +31204448529

E-mail:a.leeuwis@vumc.nl

Word count abstract: 150

Total word count text: 3388

References: 50

Tables: 4 tables 


\section{Abbreviations}

$A D$

Alzheimer's disease

PCASL Pseudo-continuous arterial spin labeling

CBF Cerebral blood flow

$\mathrm{MCl} \quad$ Mild cognitive impairment

MMSE Mini mental state examination

MRI Magnetic resonance imaging

PVC Partial volume corrected

SCD Subjective cognitive decline

WMH White matter hyperintensities 


\section{Introduction}

Alzheimer's disease (AD) is the most common neurodegenerative disease that causes dementia. Hallmark of $A D$ is severe cognitive impairment with interference in daily living. In addition to structural brain changes such as volume loss, AD patients have decreased cerebral blood flow (CBF) [1-3]. Regional CBF mapping can be accomplished with MRIbased arterial spin labeling (ASL). ASL is a non-invasive MRI-technique that uses magnetically labeled water as a tracer for blood flow.

Decreased CBF is thought to reflect neuronal dysfunction and synaptic failure, the latter is considered to be the best correlate of cognitive decline in AD [4-7]. Decreased CBF as a reflection of synaptic failure is possibly one of the determinants of cognitive impairment. In a former study, we found that in mild cognitive impairment $(\mathrm{MCl})$ and $A D$ patients lower ASLmeasured CBF was related to more severe global cognitive impairment (measured with the Mini-Mental State Examination (MMSE)) [3]. Several previous studies have investigated the association between CBF and cognitive impairment and found a relationship between lower CBF and worse cognitive performance [3,8-11]. Comparability is hampered however, by small sample sizes and the use of only a cognitive screening test, or a few neuropsychological tests to evaluate cognitive impairment.

Based on earlier findings, we hypothesized that whole-brain and regional CBF would correlate with cognitive functioning in a memory clinic population. We expected this association most prominently in AD providing support for ASL-CBF as a measure for disease severity. To test this hypothesis, we investigated the associations between ASL-CBF and performance in specific cognitive domains in a large sample of patients with subjective cognitive decline (SCD), $\mathrm{MCl}$ and $\mathrm{AD}$ using an extensive and standardized neuropsychological test battery. 


\section{Methods}

\subsection{Subjects}

We included 399 patients (143 SCD, $95 \mathrm{MCl}, 161 \mathrm{AD}$ patients) with available ASL and standardized neuropsychological assessment from the memory clinic based Amsterdam Dementia Cohort [12]. All patients visited our memory clinic between October 2010 and November 2012 and underwent standardized brain MR imaging at 3T, organized in a oneday standardized dementia screening that included medical history, physical and neurological examinations, screening laboratory tests and neuropsychological assessment. Clinical diagnosis was established by consensus in a multidisciplinary team [12]. AD patients met the NINCDS-ADRDA criteria (proposed by National Institute of Neurological and Communicative Disorders and Stroke and the Alzheimer's Disease and Related Disorders Association) for probable AD [13], and also met the core clinical criteria for probable AD proposed by the National Institute on Aging-Alzheimer's Association (NIA-AA) workgroup [14]. Diagnosis of $\mathrm{MCl}$ was based on the Petersen and NIA-AA criteria for $\mathrm{MCI}[15,16]$. Patients were considered to have SCD when they presented with cognitive complaints, and results of clinical assessments were normal (i.e. criteria for $\mathrm{MCl}$ or psychiatric disorder were not fulfilled and other underlying neurological or psychiatric diseases were ruled out) $[17,18]$. For all patients, the presence of vascular risk factors (i.e. hypertension, hypercholesterolemia, and diabetes mellitus) was determined based on self-reported medical history and medication use. Smoking status was defined as never, former or current. Level of education was classified according to the system of Verhage ranging from 1 to 7 (low to highly educated) [19]. The study was approved by the medical ethics committee of the VU University Medical Center. All patients provided written informed consent for their clinical data to be used for research purposes. 


\subsection{Neuropsychological assessment}

Cognitive functioning was assessed by a standardized neuropsychological test battery. We assessed global cognition and five cognitive domains. For global cognition, we used the MMSE [20]. For memory, we used the Visual Association Test (VAT) and the total immediate recall and delayed recall of the Dutch version of the Rey Auditory Verbal Learning Test (RAVLT) [21,22]. To examine language, we used the VAT naming, category fluency (animals), the Dutch version of the Controlled Oral Word Association Test (COWAT) [letter fluency], and the comparative questions and naming condition of the Arizona Battery for Communication Disorders (ABCD) [21,23-26]. For attention we used the Trail Making Test (TMT) part A, the Letter Digit Substitution Task (LDST), the forward condition of the Digit Span and the Stroop Test card I and II [27-30]. To examine executive functioning, we used the TMT part B, the backward condition of the Digit Span, Stroop Test card III and the Frontal Assessment Battery (FAB) [27-29,31]. To assess visuospatial functioning we used three subtests of the Visual Object and Space Perception (VOSP) battery, namely (i) incomplete letters, (ii) dot counting and (iii) number location [32].

Neuropsychological data were standardized into z-scores. TMT A and B and the Stroop Test scores were log-transformed due to non-normal distribution and inverted by computing $-1^{*} z-$ score, so that higher scores imply a better performance. In patients where the TMT B was aborted ( $n=81$ ), we estimated TMT B by multiplying the time needed to complete TMT A with the mean $B / A$ index. The mean $B / A$ index for all patients who completed both TMT $A$ and $\mathrm{B}(n=318)$ was 2.99 . On the other tests, 1 to $11 \%$ of the test scores were missing and these scores were not imputed. Raw neuropsychological test scores were standardized into z-scores across the entire group. Subsequently, available test scores were averaged to create five cognitive domains (i.e. memory, language, attention, executive functioning and visuo-spatial functioning).

\subsection{MRI protocol}

MR imaging was performed on a 3T whole body MR system (Signa HDxt, GE Medical Systems Milwaukee, WI, USA) using an 8-channel head coil. The MRI protocol included T1weighted, T2-weighted, fluid attenuated inversion recovery (FLAIR) and gradient echo T2*weighted images. Global cortical atrophy (GCA) was defined on axial FLAIR images (range: $0-3)$ [33] and the severity of white matter hyperintensities (WMH) using the Fazekas scale was determined on the FLAIR sequence (possible range: 0-3) [34], both were dichotomized into absent (0-1) or present (2-3). Medial temporal lobe atrophy (MTA) was determined on coronal T1-weighted images using the Scheltens scale (range: 0-4) [35], the mean of left and right MTA scores were dichotomized into MTA absent $(<1.5)$ or MTA present $(\geq 1.5)$. Lacunes 
were defined as deep lesions $(3-15 \mathrm{~mm})$ with CSF-like signal on all sequences. Lacunes were scored as absent or present.

Pseudo-continuous ASL (pcASL) perfusion images (3D-FSE acquisition with background suppression, post-label delay $2.0 \mathrm{~s}$, echo time $=9 \mathrm{~ms}$, repetition time $=4.8 \mathrm{~s}$, spiral readout 8 arms x 512 samples; $36 \times 5.0 \mathrm{~mm}$ axial slices, $3.2 \times 3.2 \mathrm{~mm}$ in-plane resolution, reconstructed pixel size $1.7 \times 1.7 \mathrm{~mm}$, acquisition time 4 minutes) were calculated using a single compartment model after the subtraction of labeled from control images [36].

\subsection{Pre-processing and MRI data analysis}

Both T1-weighted and pcASL images were corrected for gradient non-linearities in all three directions. Further data analyses were carried out using FSL (version 4.1; http://www.fmrib.ox.ac.uk/fsl). Pre-processing of T1 images consisted of non-brain tissue removal [37], linear registration to standard space [38] and tissue segmentation [39]. PcASL images were linearly registered to the brain-extracted T1 images. The brain mask was used to calculate uncorrected mean whole-brain CBF. Partial volume estimates were transformed to the ASL data space and used in a regression algorithm [40], using a Gaussian kernel of $9.5 \mathrm{~mm}$ full width at half maximum, to create partial volume corrected (PVC) cortical and white matter CBF maps. Partial volume estimates were subsequently used as a weighting factor to calculate mean cortical CBF. Additionally, the MNI152 atlas and the Harvard-Oxford cortical atlas (both part of FSL) were used to create regions-of-interest (ROIs) of the frontal, parietal, temporal and occipital brain areas, to extract mean regional uncorrected and PVC CBF values (Figure 1).

Figure 1: Regions-of-interest (ROls) of the frontal (yellow), parietal (green), temporal (blue) and occipital lobe (red) following the MNI152 atlas and the Harvard-Oxford cortical atlas.

\subsection{Statistics}

PASW Statistics 22.0 for Mac (SPSS Inc., Chicago, IL) was used for all statistical analyses. Analyses of variance (ANOVA) and Pearson $x^{2}$ tests were performed to compare groups when appropriate. ANOVA's were performed with age, gender and education as covariates. We then used linear regression analyses with CBF as independent variable, and cognitive domains as dependent variables (separate models for each cognitive domain). We adjusted for diagnosis (using dummy variables), age, gender, education, $\mathrm{WMH}$ and lacunes. To check if associations with CBF differed according to diagnostic group, interaction terms (dummydiagnosis ${ }^{*} \mathrm{CBF}$ ) were included in the model. When we found an interaction between diagnosis and CBF ( $p \leq 0.05)$, results were subsequently stratified for diagnosis and the standardized beta (st $\beta$ ) was displayed for each diagnostic group separately. When no 
significant interaction was found, the interaction term was removed from the model and we report overall st $\beta$. The level of significance was set at $p<0.05$.

\section{Results}

Demographic data and MRI results are summarized per diagnostic group in Table 1. Patients with SCD were younger than $\mathrm{MCl}$ and $\mathrm{AD}$ patients. Furthermore, $\mathrm{AD}$ patients were more often female than patients with $\mathrm{MCl}$ and SCD and were less educated than patients with SCD.

AD patients had more severe GCA and MTA than patients with $\mathrm{MCl}$ and SCD. Furthermore, $A D$ and $\mathrm{MCl}$ patients had more often $\mathrm{WMH}$ than patients with $S C D$, and $\mathrm{MCl}$ patients had more often lacunes than AD and SCD patients. Whole-brain PVC cortical CBF differed between groups $(p<0.01)$. Post-hoc comparisons showed that AD patients had lower PVC cortical CBF than $\mathrm{MCl}$ patients, who in turn had lower PVC cortical CBF than individuals with SCD. When we evaluated regional CBF, results were comparable.

Figure 2: Examples of uncorrected whole-brain CBF maps in subject with SCD (56-year-old man, MMSE: 30, mean uncorrected CBF: $41 \mathrm{~mL} / 100 \mathrm{~g} / \mathrm{min}$ ), patient with $\mathrm{MCl}$ (63-year-old woman, MMSE: 25 , mean uncorrected CBF: $30 \mathrm{~mL} / 100 \mathrm{~g} / \mathrm{min}$ ), and patient with AD (51-yearold man, MMSE: 18, mean uncorrected CBF: $25 \mathrm{~mL} / 100 \mathrm{~g} / \mathrm{min})$. Red to yellow/green colours represent $\mathrm{CBF}$ in millilitres per $100 \mathrm{~g}$ per minute.

Table 2 shows the raw neuropsychological test results and the z-scores of the cognitive domains per diagnosis. Adjusted for age, gender and education, AD patients had lower scores on all neuropsychological tests than patients with $\mathrm{MCl}$ and SCD. In addition, patients with $\mathrm{MCl}$ scored worse than SCD-patients on memory, attention, language and executive functions, but not on visuo-spatial functioning.

\subsection{Association between PVC cortical CBF and cognitive domains}

Table 3 shows the associations between whole-brain and regional PVC cortical CBF and performance in specific cognitive domains.

Adjusted for diagnosis, age, gender, education, $\mathrm{WMH}$ and lacunes in linear regression analyses, we found associations between whole-brain PVC cortical CBF and all cognitive domains (st $\beta$ 's $=0.07-0.14$, all $p<0.05$ ). These associations were attributable to a widespread reduction in $\mathrm{CBF}$ as we found associations between regional CBF with global cognition, memory, attention, visuo-spatial functioning, executive functioning and CBF. These associations were found for all regions, except for a trend between PVC occipital CBF and memory (st $\beta=0.06, p=0.06$ ), and for frontal CBF and attention (st $\beta=0.07, p=0.08$ ). 
There were significant interactions between PVC cortical CBF in all regions and diagnosis for language $(p<.01)$. After stratification, we found strong associations in AD patients (significant associations in all brain regions; st $\beta=0.24-0.32, p<0.001$ ), but not in $\mathrm{MCl}$ or SCD. Additionally, we found interactions between PVC parietal CBF and diagnosis for global cognition and executive functioning. After stratification we again observed strong associations in AD patients (PVC parietal CBF global cognition: $\operatorname{st} \beta=0.23, p<0.001$ and PVC parietal CBF executive functioning: $s t \beta=0.25, p<0.001$ ), while there were no significant associations in SCD or $\mathrm{MCl}$.

Figure 3: Scatterplot of PVC parietal CBF against executive functioning.

\subsection{Association between uncorrected CBF and cognitive domains}

Subsequently, we repeated the analysis for whole-brain and regional uncorrected CBF estimations (table 4). These analyses largely showed a similar pattern of associations, with an even stronger preference for the strongest associations between decreased CBF and cognitive impairment to occur in the dementia stage. Moreover, these associations appeared to be more prominent than for PVC CBF.

\section{Discussion}

The main finding of this paper is that reductions in CBF are associated with cognitive functioning in all cognitive domains and across the full spectrum of cognitive decline, but most prominently in the stage of $A D$ dementia. We observed these associations for both whole-brain and regional CBF and using both PVC cortical and uncorrected estimates of CBF.

Among the limitations of this study may be the use of partial volume correction. Although in theory it might be preferred to use PVC cortical CBF maps, the main drawback is no consensus on which method is best to correct for PVE [41]. The presence of cerebral atrophy in AD makes interpretation of ASL data complicated. An observation of cortical hypoperfusion could simply mirror cerebral atrophy. Therefore, in this study we used both uncorrected CBF, as well as PVC cortical CBF (actual grey matter CBF) to determine if the associations between $\mathrm{CBF}$ and cognition remained after correcting for PVE. In our previous work, we showed that CBF consistently increased after PVE but the proportional differences remained similar across groups [3]. In the present study, the uncorrected and PVC cortical CBF also yielded comparable results, which suggests that the detected associations of CBF with cognitive functioning are not merely a result of cerebral atrophy. Moreover, the most 
important difference between PVC cortical and uncorrected CBF estimates was that the specificity of the associations for the $A D$ stage was even more clear in the uncorrected estimates. This provides further proof that the uncorrected CBF estimates measure more than atrophy, since associations between atrophy and cognition tend to be more strong in the earlier, non-demented disease stages. Our results show a strong association between uncorrected CBF estimates (as available from the scanner in clinical practice) and disease severity, suggesting that PVE is not necessary to monitor disease severity in AD patients. ASL-MRI may therefore be a promising tool in the clinical practice.

Other possible limitations include that we did not scan with several delay times to account for differences in travel times between groups. However, we did use an age-adjusted delay time of 2.0 [42], which is assumed to be suitable to account for delayed blood arrival to the brain tissue. No correction for possible confounders on ASL-measured-CBF such as caffeineintake, smoking and vasoactive medication were applied. Furthermore, we used large ROIs which may have obscured subtle regional associations. On the other hand, the use of smaller ROIs give less accurate and less reliable CBF estimates, because of the limitations of the low signal-to-noise ratio (SNR) and spatial resolution of ASL and results of larger ROls may considered to be more robust [43]. The inclusion of relatively young patients could limit the generalizability of our findings to elderly $A D$ patients and although we view the groups of SCD, $\mathrm{MCl}$, and $A D$ in some way as a continuum, this is not self-evident, as some of these patients will remain stable or develop non-AD dementias. Finally, the cross-sectional design prevents us from drawing conclusions about the future disease course of these patients, especially for the $\mathrm{MCl}$-patients in this cohort. Among the strengths are the large cohort of $S C D, M C l$ and $A D$ patients with available pseudo-continuous ASL-MRI, which was obtained according to a standardized protocol. The use of a standardized neuropsychological test battery allowed looking at specific cognitive domains.

We found consistent associations of ASL-CBF and cognitive impairment in AD, while associations in $\mathrm{MCl}$ and $\mathrm{SCD}$ were less obvious. Previous literature suggests that functional and metabolic markers, such as glucose metabolism and CBF, show increasing changes during the progression from pre-dementia stages to $\mathrm{MCl}$ and finally the dementia stage of $A D$ $[2,3,44,45]$. Our findings suggests that CBF may be less sensitive to early brain changes, but may have particular value in reflecting disease severity in more advanced disease stages. This suggests that CBF alterations and hypometabolism continue to change along the disease process of $A D$, without reaching a plateau in an early disease stage $[44,46]$.

In this study we had an extensive and standardized neuropsychological test battery, covering five major cognitive domains. We found that $\mathrm{CBF}$, both whole-brain and in specific regions, 
was associated with functioning in all cognitive domains. Earlier studies describing associations between CBF and cognitive impairment often focused merely on screening instruments (MMSE) or a few neuropsychological tests only [3,8-10]. Chao et al. [11] investigated associations between ASL-CBF and cognitive domains, but only in $\mathrm{MCl}-$ patients. They found that $\mathrm{MCl}$ patients with a different pattern of cognitive impairment (i.e. memory or executive functioning) exhibited specific patterns of hypoperfusion. In our study, we expected to find associations of reduced CBF in a specific anatomical region and cognitive impairment in a specific domain. By contrast, our results suggest a more global or nonspecific effect of CBF on cognitive domains, indicating that decreased CBF in a particular region does not have a localized effect on a cognitive domain. These results support the hypothesis that global cognitive impairment in $A D$ patients is related to widespread brain changes. The strongest associations were observed in the stage of $A D$, when a lot of damage to the brain has occurred, and the relationship between cognitive impairments and the regional distribution of disease is less obvious. A second explanation of our results could be that although cognitive tests are selected to measure a specific cognitive domain, reality is that each test taps on more than one cognitive domain. For example worse performance on the Trail Making Test $B$ not only measures executive functioning, but also requires attention and relies heavily on intact visuo-spatial functioning. The latter could explain the association between reduced $\mathrm{CBF}$ in the posterior regions and executive functioning. Another example is that tests to assess visuo-spatial functioning (i.e. Visual Object and Space Perception (VOSP) battery) tap on a variety of abilities, such as visual and color discrimination, visuo-perceptual organization, visual construction and visual neglect. In addition, they require intact planning, organization and sequencing (i.e. executive functioning). This long list of cognitive functions may explain widespread associations between VOSP tests and reduced CBF.

In particular for parietal CBF, we found that associations with global cognition and executive functioning were most prominent in $A D$ patients. This seems in line with previous findings that $\left[{ }^{18} \mathrm{~F}\right] \mathrm{FDG}-\mathrm{PET}$-hypometabolism in AD is most pronounced in the posterior regions [47]. Moreover, these findings also seem in line with previous longitudinal findings that the posterior regions are associated with cognitive decline in AD patients $[48,49]$. Changes in CBF and glucose metabolism are closely linked, and a decrease in CBF is thought to reflect synaptic failure $[5,6]$. Synaptic failure is thought to cause network disturbance and connectivity research shows that the posterior brain region is a highly active network region [50]. Probably the association that we found between parietal CBF and cognitive impairment reflects network disruption. Finally, we found a strong association between lower CBF in all regions and worse performance on language in $A D$ patients. These results are consistent 
with earlier findings and provides further evidence for the reflection of network disruption in $A D$ [50], or that multiple brain regions contribute to different aspects of cognitive processes.

Earlier studies have well established the association between decreased CBF and AD. However, it is still not completely clarified whether decreased CBF is a cause, consequence or epiphenomenon of underlying AD pathology. Future research with repeated measurements of CBF could explore the relationship between change in CBF and cognition in the earlier non-demented disease stage and in more advanced disease stages. ASL could be of additional value in this line of research. In addition, whereas the detection of amyloid in living patients has a large diagnostic value, the level of deposition does not correlate well with cognitive impairment [51]. It is therefore not certain whether amyloid represents a useful outcome measure in clinical trials. Our results suggest that ASL-measured-CBF is a functional marker of disease severity. In addition to the absolute units of CBF measurement, ASL-measured-CBF could be a possible useful imaging marker of therapeutic efficacy in clinical trials. Finally, future research could exploit the potential for a (non-)pharmacological treatment for the regulation of $\mathrm{CBF}$ and prevention of $\mathrm{AD}$. Identifying the possible mechanism underlying the effect of decreased CBF on cognition, could support the recommendation of changing lifestyle factors, such as regular exercise, as a preventative therapy to prevent or delay dementia.

In conclusion, our study investigated ASL-CBF in the entire cognitive spectrum - from SCD to $A D$ - and our results show associations across all cognitive domains. Of note, these associations were strongest for $A D$ patients. Our findings support the potential role of $C B F$ as a functional marker of disease severity, with ASL as non-invasive, easily-obtained method of CBF measurement.

\section{Acknowledgements}

Research of the VUmc Alzheimer center is part of the neurodegeneration research program of the Neuroscience Campus Amsterdam. The VUmc Alzheimer center is supported by Alzheimer Nederland and Stichting VUmc fonds. The clinical database structure was developed with funding from Stichting Dioraphte.

We acknowledge the support from the Netherlands CardioVascular Research Initiative: the Dutch Heart Foundation (CVON 2012-06 Heart Brain Connection), Dutch Federation of University Medical Centres, the Netherlands Organisation for Health Research and Development and the Royal Netherlands Academy of Sciences. 


\section{Disclosures}

A.E. Leeuwis, M.R. Benedictus, J.P.A. Kuijer, M.A.A. Binnewijzend, A.M. Hooghiemstra, S.C.J. Verfaillie, T. Koene report no disclosures.

Ph. Scheltens has acquired grant support (for the institution) from GE Healthcare, Danone Research, Piramal and MERCK. In the past 2 years he has received consultancy/speaker fees (paid to the institution) from Lilly, GE Healthcare, Novartis, Sanofi, Nutricia, Probiodrug, Biogen, Roche, Avraham and EIP Pharma.

F. Barkhof serves as a consultant for Biogen-Idec, Janssen Alzheimer Immunotherapy, Bayer-Schering, Merck-Serono, Roche, Novartis, Genzume and Sanofi-aventis. F. Barkhof has received sponsoring from EU-H2020, NOW, SMSR, TEVA, Novartis, Toshiba and Imi. F. Barkhof serves on the editorial boards of Radiology, Brain, Neuroradiology, MSJ and Neurology.

N.D. Prins serves on the advisory board of Boehringer Ingelheim, Forum, and Probiodrug and has provided consultancy services for Sanofi and Takeda. He has been a speaker at symposia organised by Janssen and Novartis. N.D. Prins receives research support from Alzheimer Nederland (project number WE.03-2012-02). N.D. Prins is CEO and co-owner of the Alzheimer Research Center, Amsterdam, the Netherlands.

W.M. van der Flier performs contract research for Boehringer Ingelheim and has been an invited speaker at Boehringer Ingelheim. Research programs of W.M. van der Flier have been funded by ZonMW, NWO, EU-FP7, Alzheimer Nederland, Cardiovasculair Onderzoek Nederland, stichting Dioraphte, Gieskes-Strijbis fonds, Boehringer Ingelheim, Piramal Neuroimaging, Roche BV, Janssen Stellar, Combinostics. All funding is paid to her institution. 


\section{References}

[1] Alsop DC, Detre JA, Grossman M. Assessment of Cerebral Blood Flow in Alzheimer's Disease by Spin-Labeled Magnetic Resonance Imaging. Ann Neurol 2000;47:93-100.

[2] Dai W, Lopez OL, Carmichael OT, Becker JT, Kuller LH, Gach HM. Mild Cognitive Impairment and Alzheimer Disease : Patterns of Altered Cerebral Blood Flow at MR Imaging. Radiology 2009;250:856-66.

[3] Binnewijzend MA, Kuijer JP, Benedictus MR, van der Flier WM, Wink AM, Wattjes MP, et al. Cerebral Blood Flow Measured Arterial Spin-labeling MR Imaging in Alzheimer Disease and Mild Cognitive Impairment. Radiology 2013;267:221-30.

[4] Chen Y, Wolk D a, Reddin JS, Korczykowski M, Martinez PM, Musiek ES, et al. Voxellevel comparison of arterial spin-labeled perfusion MRI and FDG-PET in Alzheimer disease. Neurology 2011;77:1977-85. doi:10.1212/WNL.0b013e31823a0ef7.

[5] Jueptner M, Weiller C. Review: Does measurement of regional cerebral blood flow reflect synaptic activity - Implications for PET and fMRI. Neuroimage 1995;2:148-56.

[6] Musiek ES, Chen Y, Korczykowski M, Saboury B, Martinez PM, Reddin JS, et al. Direct comparison of FDG-PET and ASL-MRI in Alzheimer's Disease. Alzheimer's Dement 2013;8:51-9. doi:10.1016/j.jalz.2011.06.003.Direct.

[7] Palop JJ, Mucke L. Amyloid-beta- induced neuronal dysfunction in Alzheimer' s disease : from synapses toward neural networks. Nat Publ Gr 2010;13. doi:10.1038/nn.2583.

[8] Kitagawa K, Oku N, Kimura Y, Yagita Y, Sakaguchi M, Hatazawa J, et al. Relationship between cerebral blood flow and later cognitive decline in hypertensive patients with cerebral small vessel disease. Hypertens Res 2009;32:816-20.

doi:10.1038/hr.2009.100.

[9] Wierenga CE, Dev SI, Shin DD, Clark LR, Bangen KJ, Jak AJ, et al. Effect of mild cognitive impairment and APOE genotype on resting cerebral blood flow and its association with cognition. J Cereb Blood Flow Metab 2012;32:1589-99. doi:10.1038/jcbfm.2012.58. 
[10] Montaldi D, Brooks D, McCool J, Wyper D, Patterson J, Barron E, et al. A study of regional cerebral blood flow and cognitive performance in Alzheimer's disease. $\mathrm{J}$ Neurol Neurosurg Psychiatry 1990;53:1182-7.

[11] Chao LL, Pa J, Duarte A, Schuff N, Weiner MW, Kramer JH, et al. Patterns of Cerebral Hypoperfusion in Amnestic and Dysexecutive MCl. Alzheimer Dis Assoc Disord 2009;23:245-52.

[12] Van der Flier WM, Pijnenburg $Y$ a L, Prins N, Lemstra AW, Bouwman FH, Teunissen $\mathrm{CE}$, et al. Optimizing patient care and research: the Amsterdam Dementia Cohort. J Alzheimers Dis 2014;41:313-27. doi:10.3233/JAD-132306.

[13] McKhann G, Drachman D, Folstein M, Katzman R. Clinical diagnosis of Alzheimer's disease: Report of the NINCDS-ADRDA Work Group under de auspices of Department of Health and Human Services Task Force on Alzheimer's disease. Neurology 1984;34:939-44.

[14] McKhann GM, Knopman DS, Chertkow H, Hyman BT, Jack CR, Kawas CH, et al. The diagnosis of dementia due to Alzheimer's disease: Recommendations from the National Institute on Aging-Alzheimer's Association workgroups on diagnostic guidelines for Alzheimer's disease. Alzheimer's Dement 2011;7:263-9. doi:10.1016/j.jalz.2011.03.005.The.

[15] Petersen RC, Stevens JC, Ganguli M, Tangalos EG, Cummings JL, Dekosky ST, et al. Practice parameter: Early detection of dementia: Mild Cognitive Impairment (an evicence-based review). Neurology 2001;56:1133-42.

[16] Albert MS, DeKosky ST, Dickson D, Dubois B, Feldman HH, Fox NC, et al. The diagnosis of mild cognitive impairment due to Alzheimer's disease: recommendations from the National Institute on Aging-Alzheimer's Association workgroups on diagnostic guidelines for Alzheimer's disease. Alzheimers Dement 2011;7:270-9. doi:10.1016/j.jalz.2011.03.008.

[17] Jessen F, Amariglio RE, van Boxtel M, Breteler M, Ceccaldi M, Chételat G, et al. A conceptual framework for research on subjective cognitive decline in preclinical Alzheimer's disease. Alzheimers Dement 2014;10:844-52. doi:10.1016/j.jalz.2014.01.001. 
[18] Schoonenboom NSM. Cerebrospinal fluid markers for differential dementia diagnosis in a large memory clinic cohort. Neurology 2012;78:47-54.

[19] Verhage F. Intelligentie en leeftijd: Onderzoek bij Nederlanders van 12-77 jaar [in Dutch]. Van Gorcum Assen; 1964.

[20] Folstein MF, Folstein SE, Mchugh PR. Mini-Mental State - Practical Method for Grading Cognitive State of Patients for Clinician. J Psychiatr Res 1975;12:189-98.

[21] Lindeboom J, Schmand B, Tulner L, Walstra G, Jonker C. Visual association test to detect early dementia of the Alzheimer type. J Neurol Neurosurg Psychiatry 2002;73:126-33.

[22] Saan R, Deelman B. De 15-woordentest A en B (een voorlopige handleiding) [in Dutch]. Groningen, NEderland: 1986.

[23] Luteijn F, der Ploeg FAE. GIT, Groninger Intelligence Test: Manual 1982.

[24] Bayles K, Tomoeda CK. ABCD: Arizona Battery for Communication Disorders in Dementia. Tucson, AZ: Canyonlands Publishing; 1991.

[25] Schmand B, Groenink SC, Dungen M Van Den. Letterfluency : psychometrische eigenschappen en Nederlandse normen. Tijdschr Gerontol Geriatr 2008;39:64-76.

[26] Van der Elst W, Van Boxtel MPJ, Van Breukelen GJP, Jolles J. Normative data for the Animal, Profession and Letter M Naming verbal fluency tests for Dutch speaking participants and the effects of age, education, and sex. J Int Neuropsychol Soc 2006;12:80-9. doi:10.1017/S1355617706060115.

[27] Reitan RM. Validity of the Trail Making Test as an indicator of organic brain damage. Percept Mot Skills 1958;8:271-6.

[28] Lindeboom J, Matto D. Digit series and Knox cubes as concentration tests for elderly subjects [in Dutch]. Tijdschr Gerontol Geriatr 1994;25:63-8.

[29] Van der Elst W, Van Boxtel MPJ, Van Breukelen GJP, Jolles J. The Stroop color-word test: influence of age, sex, and education; and normative data for a large sample across the adult age range. Assessment 2006;13:62-79.

doi:10.1177/1073191105283427. 
[30] Van der Elst W, van Boxtel MPJ, van Breukelen GJP, Jolles J. The Letter Digit Substitution Test: normative data for 1,858 healthy participants aged 24-81 from the Maastricht Aging Study (MAAS): influence of age, education, and sex. J Clin Exp Neuropsychol 2006;28:998-1009. doi:10.1080/13803390591004428.

[31] Dubois B, Slachevsky A, Litvan I, Pillon B. The FAB: A Frontal Assessment Battery at bedside. Neurology 2000;55:1621-6.

[32] Warrington E, James M. The visual object and space perception battery. Bury St. Edmunds, UK: 1991.

[33] Pasquier F, Leys D, Weerts JGE, Mounier-Vehier F, Barkhof F, Scheltens P. Interand intraobserver reproducibility of cerebral atrophy assessment on MRI scans with hemispheric infarcts. Eur J Neurol 1996;36:268-72.

[34] Fazekas F, Chawluk JB, Hurtig HI, Zimmerman RA. MR Signal Abnormalities at 1.5 T in Alzheimer's Dementia and Normal Aging. Am J Neuroradiol 1987;8:421-6.

[35] Scheltens P, Launer LJ, Barkhof F, Weinstein HC, Gool WA van. Visual assessment of medial temporal lobe atrophy on magnetic resonance imaging: interobserver reliability. J Neurol 1995;242:557-60.

[36] Buxton RB, Frank LR, Wong EC, Siewert B, Warach S, Edelman RR. A General Kinetic Model for Quantitative Perhsion Imaging with Arterial Spin Labeling. Magn Reson Med 1998:383-96.

[37] Smith SM. Fast robust automated brain extraction. Hum Brain Mapp 2002;17:143-55. doi:10.1002/hbm.10062.

[38] Jenkinson M, Smith S. A global optimisation method for robust affine registration of brain images. Med Image Anal 2001;5:143-56.

[39] Zhang Y, Brady M, Smith S. Segmentation of Brain MR Images Through a Hidden Markov Random Field Model and the Expectation-Maximization Algorithm. IEEE Trans Med Imaging 2001;20:45-57.

[40] Asllani I, Borogovac A, Brown TR. Regression algorithm correcting for partial volume effects in arterial spin labeling MRI. Magn Reson Med 2008;60:1362-71. doi:10.1002/mrm.21670. 
[41] Hutton BF, Thomas BA, Erlandsson K, Bousse A, Reilhac-laborde A, Kazantsev D, et al. Nuclear Instruments and Methods in Physics Research $A$ What approach to brain partial volume correction is best for PET / MRI ? Nucl Inst Methods Phys Res A 2013;702:29-33. doi:10.1016/j.nima.2012.07.059.

[42] Campbell AM, Beaulieu C. Pulsed arterial spin labeling parameter optimization for an elderly population. J Magn Reson Imaging 2006;23:398-403. doi:10.1002/jmri.20503.

[43] Petersen ET, Zimine I, Ho Y-CL, Golay X. Non-invasive measurement of perfusion: a critical review of arterial spin labelling techniques. $\mathrm{Br} J$ Radiol 2006;79:688-701. doi:10.1259/bjr/67705974.

[44] Jack CR, Knopman DS, Jagust WJ, Petersen RC, Weiner MW, Aisen PS, et al. Tracking pathophysiological processes in Alzheimer's disease: an updated hypothetical model of dynamic biomarkers. Lancet Neurol 2013;12:207-16. doi:10.1016/S1474-4422(12)70291-0.

[45] Alexopoulos P, Sorg C, Förschler A, Grimmer T, Skokou M, Wohlschläger A, et al. Perfusion abnormalities in mild cognitive impairment and mild dementia in Alzheimer's disease measured by pulsed arterial spin labeling MRI. Eur Arch Psychiatry Clin Neurosci 2012;262:69-77. doi:10.1007/s00406-011-0226-2.

[46] Landau SM, Mintum MA, Joshi AD, Koeppe RA, Petersen RC, Aisen PS, et al. Amyloid deposition, hypometabolism, and longitudinal cognitive decline. Ann Neurol 2013;72:578-86. doi:10.1002/ana.23650.Amyloid.

[47] Mosconi L, Tsui WH, Herholz K, Pupi a., Drzezga a., Lucignani G, et al. Multicenter Standardized 18F-FDG PET Diagnosis of Mild Cognitive Impairment, Alzheimer's Disease, and Other Dementias. J Nucl Med 2008;49:390-8. doi:10.2967/jnumed.107.045385.

[48] Hanyu H, Sato T, Hirao K, Kanetaka H, Iwamoto T, Koizumi K. The progression of cognitive deterioration and regional cerebral blood flow patterns in Alzheimer's disease: a longitudinal SPECT study. J Neurol Sci 2010;290:96-101. doi:10.1016/j.jns.2009.10.022.

[49] Xekardaki A, Rodriguez C, Montandon M, Toma S, Tombeur E, Hermann FR, et al. Arterial Spin Labeling May Contribute to the Prediction of Cognitive Deterioration in. Neuroradiology 2015;274:490-9. 
[50] Dennis E, Thompson P. Functional brain connectivity using fMRI in aging and Alzheimer's disease. Neuropsychol Rev 2014;24:49-62. doi:10.1007/s11065-0149249-6.Functional.

[51] Jack CR, Lowe VJ, Weigand SD, Wiste HJ, Senjem ML, Knopman DS, et al. Serial PIB and MRI in normal , mild cognitive impairment and Alzheimer's disease : implications for sequence of pathological events in Alzheimer's disease. Brain 2009;132:1355. doi:10.1093/brain/awp062. 


\begin{tabular}{|c|c|c|c|c|}
\hline & Total $(n=399)$ & $\operatorname{SCD}(n=143)$ & $\mathrm{MCl}(\mathrm{n}=95)$ & $A D(n=161)$ \\
\hline Age & $63.53 \pm 8.23$ & $59.69 \pm 8.69$ & $65.24 \pm 7.28^{a}$ & $65.93 \pm 7.04^{a}$ \\
\hline Women, n (\%) & $184(46.1 \%)$ & $63(44.1 \%)$ & $33(34.7 \%)$ & $88(54.7 \%)^{a b}$ \\
\hline Education & $5.15 \pm 1.29$ & $5.45 \pm 1.19$ & $5.14 \pm 1.35$ & $4.89 \pm 1.30^{\mathrm{a}}$ \\
\hline MMSE & $24.75 \pm 4.78$ & $28.22 \pm 1.53$ & $26.57 \pm 1.93^{\mathrm{a}}$ & $20.60 \pm 4.76^{\mathrm{ab}}$ \\
\hline \multicolumn{5}{|l|}{ Vascular risk factors } \\
\hline Hypertension, n (\%) & $136(34.1 \%)$ & $39(27.3 \%)$ & $39(41.1 \%)^{a}$ & $58(36 \%)$ \\
\hline Hypercholesterolemia, n (\%) & $106(26.6 \%)$ & $26(18.2 \%)$ & $36(37.9 \%)^{a}$ & $44(27.3 \%)$ \\
\hline Diabetes mellitus, $\mathrm{n}(\%)$ & $36(9 \%)$ & $12(8.4 \%)$ & $13(13.7 \%)$ & $11(6.8 \%)$ \\
\hline \multicolumn{5}{|l|}{ Smoking status: } \\
\hline Never, n (\%) & $161(40.4 \%)$ & $63(44.1 \%)$ & $42(44.2 \%)$ & $56(34.8 \%)$ \\
\hline Former, n (\%) & $170(43.8 \%)$ & $61(43.5 \%)$ & $34(37.3 \%)$ & $75(47.7 \%)$ \\
\hline Current, n (\%) & $57(14.3 \%)$ & $16(11.2 \%)$ & $15(15.8 \%)$ & $26(16.1 \%)$ \\
\hline \multicolumn{5}{|l|}{ MRI characteristics } \\
\hline GCA (\%) & $46(11.5 \%)$ & $3(2.1 \%)$ & $6(6.3 \%)$ & $37(23 \%)^{a b}$ \\
\hline MTA (\%) & $52(13 \%)$ & $0(0 \%)$ & $6(6.3 \%)^{a}$ & $46(28.6 \%)^{a b}$ \\
\hline WMH (\%) & $82(20.6 \%)$ & $12(8.4 \%)$ & $28(29.5 \%)^{a}$ & $42(26.1 \%)^{a}$ \\
\hline Lacunes (\%) & $31(7.8 \%)$ & $6(4.2 \%)$ & $16(16.8 \%)^{\mathrm{ac}}$ & $9(5.6 \%)$ \\
\hline \multicolumn{5}{|l|}{ PVC cortical CBF } \\
\hline Whole-brain & $44.72 \pm 9.87$ & $48.67 \pm 9.80$ & $44.28 \pm 9.10^{\mathrm{a}}$ & $41.47 \pm 9.16^{\mathrm{ab}}$ \\
\hline \multicolumn{5}{|l|}{ Regional PVC cortical CBF } \\
\hline Frontal & $45.35 \pm 10.61$ & $49.29 \pm 10.47$ & $44.75 \pm 10.11^{\mathrm{a}}$ & $42.20 \pm 9.94^{\mathrm{ab}}$ \\
\hline Temporal & $41.07 \pm 8.83$ & $44.54 \pm 8.88$ & $41.32 \pm 8.05^{\mathrm{a}}$ & $37.83 \pm 8.02^{\mathrm{a}}$ \\
\hline Parietal & $50.13 \pm 11.90$ & $55.35 \pm 11.53$ & $50.12 \pm 10.95^{\mathrm{a}}$ & $45.49 \pm 10.85^{\mathrm{ab}}$ \\
\hline Occipital & $50.71 \pm 11.91$ & $55.09 \pm 11.60$ & $50.32 \pm 11.11^{\mathrm{a}}$ & $47.06 \pm 11.42^{\mathrm{ab}}$ \\
\hline
\end{tabular}

AD, Alzheimer's Disease; $\mathrm{MCl}$, mild cognitive impairment; SCD, subjective cognitive decline; GCA, global cortical atrophy; MTA, medial temporal lobe atrophy; WMH, high-signal-intensity areas in white matter (based on Fazekas score); MMSE, Mini Mental State Examination; CBF, cerebral blood flow; PVC, partial volume corrected. Availability for incomplete data: SCD: Smoking status 140/143, MCl: Smoking status 91/95, GCA, 94/95; MTA 94/95; WMH 94/95; AD: Smoking status 157/161. One-way ANOVA or $X^{2}$ were performed, respectively. Data are presented as mean $\pm S D$, number (percentage). Cerebral blood flow (CBF) values in $\mathrm{mL} / 100 \mathrm{~g} / \mathrm{min}$. Significant difference $p<0.05$ to ${ }^{\mathrm{a}} \mathrm{SCD},{ }^{\mathrm{b}} \mathrm{MCl}$ and ${ }^{\mathrm{c}} \mathrm{AD}$. 
Table 2: Raw neuropsychological test performance of diagnostic groups

\begin{tabular}{|c|c|c|c|c|}
\hline & Total $(n=399)$ & $\operatorname{SCD}(n=143)$ & $\mathrm{MCl}(n=95)$ & $\mathbf{A D}(n=161)$ \\
\hline Memory (z-score) & $-0 \pm 0.9$ & $0.8 \pm 0.4$ & $0 \pm 0.5^{\mathrm{a}}$ & $-0.8 \pm 0.6^{\mathrm{ab}}$ \\
\hline VAT & $8.9 \pm 3.7$ & $11.6 \pm 0.7$ & $10.2 \pm 2.4^{\mathrm{a}}$ & $5.7 \pm 3.8^{\mathrm{ab}}$ \\
\hline RAVLT total immediate & $32.5 \pm 12.8$ & $43.6 \pm 9.4$ & $32.3 \pm 8.5^{\mathrm{a}}$ & $21.9 \pm 8^{\mathrm{ab}}$ \\
\hline RAVLT delayed & $5 \pm 4.1$ & $8.9 \pm 3$ & $4.2 \pm 2.7^{\mathrm{a}}$ & $1.8 \pm 2.2^{\mathrm{ab}}$ \\
\hline Attention (z-score) & $-0 \pm 0.8$ & $0.5 \pm 0.5$ & $0.1 \pm 0.5^{\mathrm{a}}$ & $-0.5 \pm 0.9^{\mathrm{ab}}$ \\
\hline TMT A* & $60.9 \pm 55.4$ & $35.7 \pm 13.3$ & $47.5 \pm 24$ & $93.6 \pm 75.3^{\mathrm{ab}}$ \\
\hline LDST & $38 \pm 13$ & $46 \pm 9.5$ & $39.3 \pm 10^{\mathrm{a}}$ & $27.9 \pm 11.7^{\mathrm{ab}}$ \\
\hline Digit span (forward) & $11.7 \pm 3.3$ & $13 \pm 3.2$ & $11.5 \pm 2.8^{\mathrm{a}}$ & $10.5 \pm 3.2^{\mathrm{ab}}$ \\
\hline Stroop I & $52 \pm 17.8$ & $44.3 \pm 8.3$ & $48.1 \pm 10.2$ & $62 \pm 23.2^{\mathrm{ab}}$ \\
\hline Stroop II & $75.6 \pm 32.8$ & $61.3 \pm 13.7$ & $67.5 \pm 15.5^{\mathrm{a}}$ & $95.5 \pm 43.4^{\mathrm{ab}}$ \\
\hline Language (z-score) & $-0 \pm 0.8$ & $0.3 \pm 0.5$ & $0.2 \pm 0.6$ & $-0.5 \pm 0^{\mathrm{ab}}$ \\
\hline VAT naming & $11.6 \pm 1.2$ & $11.9 \pm 0.4$ & $11.9 \pm 0.4$ & $11.1 \pm 1.7^{\mathrm{ab}}$ \\
\hline Animal fluency & $17.1 \pm 6.7$ & $21.5 \pm 5.7$ & $18.6 \pm 5.3^{a}$ & $12.3 \pm 5^{\mathrm{ab}}$ \\
\hline Letter fluency & $30.1 \pm 12.8$ & $34.9 \pm 12$ & $31.7 \pm 12$ & $24.7 \pm 12^{\mathrm{ab}}$ \\
\hline Comparative questions & $5.6 \pm 0.7$ & $5.8 \pm 0.3$ & $5.8 \pm 0.4$ & $5.4 \pm 1^{\mathrm{ab}}$ \\
\hline$A B C D$ naming & $17.1 \pm 3$ & $18.6 \pm 1.4$ & $17.8 \pm 2.1^{\mathrm{a}}$ & $15.1 \pm 3.6^{\mathrm{ab}}$ \\
\hline Visuospatial functioning (z-score) & $-0 \pm 0.8$ & $0.3 \pm 0.3$ & $0.2 \pm 0.3$ & $-0.5 \pm 1.1^{\mathrm{ab}}$ \\
\hline Number location & $8.6 \pm 1.5$ & $9.2 \pm 1$ & $9 \pm 1.14$ & $7.9 \pm 1.8^{\mathrm{ab}}$ \\
\hline Dot counting & $9.4 \pm 1.1$ & $9.8 \pm 0.4$ & $9.6 \pm 0.5$ & $8.9 \pm 1.7^{\mathrm{ab}}$ \\
\hline Fragmented letters & $17.5 \pm 4$ & $19.1 \pm 1.4$ & $18.5 \pm 1.2$ & $15 \pm 5.7^{\mathrm{ab}}$ \\
\hline Executive functioning (z-score) & $-0 \pm 0.9$ & $0.6 \pm 0.4$ & $0.1 \pm 0.5^{\mathrm{a}}$ & $-0.8 \pm 0.8^{\mathrm{ab}}$ \\
\hline Digit span (backward) & $7.8 \pm 2.8$ & $9.4 \pm 2.6$ & $7.9 \pm 2.5^{\mathrm{a}}$ & $6.3 \pm 2.4^{\mathrm{ab}}$ \\
\hline TMT B $^{*}$ & $182.6 \pm 173.9$ & $88 \pm 45.4$ & $142.2 \pm 91.5^{\mathrm{a}}$ & $299.2 \pm 219.6^{\mathrm{ab}}$ \\
\hline $\mathrm{FAB}$ & $15 \pm 3.3$ & $16.9 \pm 1.4$ & $15.9 \pm 1.8$ & $12.3 \pm 3.8^{\mathrm{ab}}$ \\
\hline Stroop III & $131.4 \pm 63.5$ & $98.6 \pm 24.1$ & $121 \pm 36.3^{\mathrm{a}}$ & $180.3 \pm 63.5^{\mathrm{ab}}$ \\
\hline
\end{tabular}

AD, Alzheimer's Disease; $M C l$, mild cognitive impairment; SCD, subjective cognitive decline; MMSE, Mini Mental State Examination; VAT, Visual Association Test; RAVLT, Rey Auditory Verbal Learning Test; TMT, Trail Making Test; LDST, Letter Digit Substitution Test; ABCD, Arizona Battery for Communication Disorders; FAB, Frontal Assessment Battery.

Z-scores allow comparison of neuropsychological test results within patients. Higher z-scores imply better performance on all tests.

Raw neuropsychological data are presented as mean \pm standard deviation. Univariate analyses of variances were performed with diagnosis as between-subject factor. Gender, age and education are entered as covariates. Significant difference $p<0.05$ to ${ }^{\mathrm{a}} \mathrm{SCD},{ }^{\mathrm{b}} \mathrm{MCl}$ and ${ }^{\mathrm{C}} \mathrm{AD}$.

*Higher scores imply worse performance. 
Table 3: Linear regression models for the association between PVC cortical CBF and cognitive domains

\begin{tabular}{|c|c|c|c|c|c|}
\hline Region & Cognitive domain & All & $\operatorname{SCD}(n=143)$ & $\operatorname{MCl}(n=95)$ & $\operatorname{AD}(n=161)$ \\
\hline \multirow[t]{6}{*}{ Whole-brain } & Global & $.10^{* *}$ & & & \\
\hline & Memory & $.07^{*}$ & & & \\
\hline & Attention & $.09^{*}$ & & & \\
\hline & Executive functioning & $.12^{* *}$ & & & \\
\hline & Visuo-spatial functioning & $.14^{* *}$ & & & \\
\hline & Language & & .01 & .11 & $.28^{* * *}$ \\
\hline \multirow[t]{6}{*}{ Parietal } & Global & & .06 & .06 & $.23^{* * *}$ \\
\hline & Memory & $.09^{* *}$ & & & \\
\hline & Attention & $.10^{*}$ & & & \\
\hline & Executive functioning & & .07 & .09 & $.25^{\star \star *}$ \\
\hline & Visuo-spatial functioning & $.18^{* * *}$ & & & \\
\hline & Language & & .01 & .10 & $.32^{\star \star *}$ \\
\hline \multirow[t]{6}{*}{ Frontal } & Global & $.10^{\star *}$ & & & \\
\hline & Memory & $.08^{* *}$ & & & \\
\hline & Attention & .07 & & & \\
\hline & Executive functioning & $.11^{* *}$ & & & \\
\hline & Visuo-spatial functioning & $.12^{*}$ & & & \\
\hline & Language & & .03 & .11 & $.30 * * *$ \\
\hline \multirow[t]{6}{*}{ Temporal } & Global & $.10^{* *}$ & & & \\
\hline & Memory & $.08^{* *}$ & & & \\
\hline & Attention & $.10^{*}$ & & & \\
\hline & Executive functioning & $.12^{* \star *}$ & & & \\
\hline & Visuo-spatial functioning & $.13^{* *}$ & & & \\
\hline & Language & & .00 & .11 & $.29^{\star \star \star}$ \\
\hline \multirow{6}{*}{ Occipital } & Global & $.08^{*}$ & & & \\
\hline & Memory & .06 & & & \\
\hline & Attention & .05 & & & \\
\hline & Executive functioning & $.10^{* *}$ & & & \\
\hline & Visuo-spatial functioning & $.18^{* * *}$ & & & \\
\hline & Language & & -.02 & .08 & $.24^{* * *}$ \\
\hline
\end{tabular}

We used linear regression analyses with PVC cortical CBF as independent variable and cognitive domains as dependent variable. Cognition is expressed as a (composite) z-score. We corrected for diagnosis (using dummy variables), age, gender and education, white matter hyperintensities and presence of lacunes. To check if associations with $\mathrm{CBF}$ differed according to diagnostic group, interaction terms (dummy-diagnosis ${ }^{*} \mathrm{CBF}$ ) were included in the model. When we found an interaction between diagnosis and CBF $(p<0.05)$, results were subsequently stratified for diagnosis and the standardized beta $(\mathrm{st} \beta)$ is displayed for each group separately. When no significant was found, the interaction term was removed from the model and the overall st $\beta$ is reported. SCD, subjective cognitive decline; $\mathrm{MCl}$, mild cognitive impairment; $A D$, Alzheimer's disease.

${ }^{*} p<0.05,{ }^{* *} p<0.01,{ }^{* * *} p<0.001$ 
Table 4: Linear regression models for the association between uncorrected CBF and cognitive domains

\begin{tabular}{|c|c|c|c|c|c|}
\hline Region & Cognitive domain & All & $\operatorname{SCD}(n=143)$ & $\operatorname{MCl}(n=95)$ & $\operatorname{AD}(n=161)$ \\
\hline \multirow[t]{6}{*}{ Whole-brain } & Global & $.11^{* *}$ & & & \\
\hline & Memory & $.08^{* *}$ & & & \\
\hline & Attention & $.11^{*}$ & & & \\
\hline & Executive functioning & $.13^{* * *}$ & & & \\
\hline & Visuo-spatial functioning & $.15^{\star *}$ & & & \\
\hline & Language & & .01 & .12 & $.31^{* * *}$ \\
\hline \multirow[t]{6}{*}{ Parietal } & Global & & .06 & .06 & $.26^{\star * *}$ \\
\hline & Memory & $.09^{* *}$ & & & \\
\hline & Attention & & .04 & .12 & $.25^{\star \star \star}$ \\
\hline & Executive functioning & & .07 & .08 & $.31^{* \star *}$ \\
\hline & Visuo-spatial functioning & $.20 * * *$ & & & \\
\hline & Language & & .01 & .12 & $.34^{* * *}$ \\
\hline \multirow[t]{6}{*}{ Frontal } & Global & $.11^{* *}$ & & & \\
\hline & Memory & $.08^{* *}$ & & & \\
\hline & Attention & .08 & & & \\
\hline & Executive functioning & $.12^{* *}$ & & & \\
\hline & Visuo-spatial functioning & $.11^{*}$ & & & \\
\hline & Language & & .03 & .12 & $.30 * * *$ \\
\hline \multirow[t]{6}{*}{ Temporal } & Global & $.13^{* \star \star}$ & & & \\
\hline & Memory & $.10^{* *}$ & & & \\
\hline & Attention & $.11^{* *}$ & & & \\
\hline & Executive functioning & $.14^{* * *}$ & & & \\
\hline & Visuo-spatial functioning & $.14^{* *}$ & & & \\
\hline & Language & & .02 & .11 & $.37^{\star \star *}$ \\
\hline \multirow[t]{6}{*}{ Occipital } & Global & & .04 & .08 & $.23^{\star \star *}$ \\
\hline & Memory & $.06^{*}$ & & & \\
\hline & Attention & & .01 & .14 & $.22^{\star *}$ \\
\hline & Executive functioning & $.10^{* *}$ & & & \\
\hline & Visuo-spatial functioning & & .05 & .12 & $.42^{\star * *}$ \\
\hline & Language & & -.01 & .07 & $.29^{* \star *}$ \\
\hline
\end{tabular}

We used linear regression analyses with uncorrected CBF as independent variable and cognitive domains as dependent variable. Cognition is expressed as a (composite) z-score. We corrected for diagnosis (using dummy variables), age, gender and education, white matter hyperintensities and presence of lacunes. To check if associations with $\mathrm{CBF}$ differed according to diagnostic group, interaction terms (dummy-diagnosis ${ }^{*} \mathrm{CBF}$ ) were included in the model. When we found an interaction between diagnosis and CBF $(p<0.05)$, results were subsequently stratified for diagnosis and the standardized beta $(\mathrm{st} \beta)$ is displayed for each group separately. When no significant was found, the interaction term was removed from the model and the overall st $\beta$ is reported. SCD, subjective cognitive decline; $\mathrm{MCl}$, mild cognitive impairment; $A D$, Alzheimer's disease.

${ }^{*} p<0.05,{ }^{* *} p<0.01,{ }^{* * *} p<0.001$ 